\title{
An algorithm to detect sea ice leads by using AMSR-E passive microwave imagery
}

\author{
J. Röhrs and L. Kaleschke \\ Institut für Meereskunde, KlimaCampus, University of Hamburg, Bundesstraße 53, 20146 Hamburg, Germany \\ Correspondence to: L. Kaleschke (lars.kaleschke@zmaw.de)
}

Received: 19 January 2010 - Published in The Cryosphere Discuss.: 22 February 2010

Revised: 24 February 2012 - Accepted: 16 March 2012 - Published: 27 March 2012

\begin{abstract}
Leads are major sites of energy fluxes and brine releases at the air-ocean interface of sea-ice covered oceans. This study presents an algorithm to detect leads wider than $3 \mathrm{~km}$ in the entire Arctic Ocean. The algorithm detects 50\% of the lead area that was visible in optical MODIS satellite images. Passive microwave imagery from the Advanced Microwave Scanning Radiometer - Earth Observation System (AMSR-E) is used, allowing daily observations due to the fact that AMSR-E does not depend on daylight or cloud conditions. Using the unique signatures of thin ice in the brightness temperature ratio between the $89 \mathrm{GHz}$ and $19 \mathrm{GHz}$ channels, the algorithm is able to detect thin ice areas in the ice cover and is optimized to detect leads. Leads are mapped for the period from 2002 to 2011 excluding the summer months, and validated qualitatively by using MODIS, Envisat ASAR, and CryoSat-2 data. Several frequently recurring large scale lead patterns are found, especially in regions where sea ice is known to drift out of the Arctic Ocean.
\end{abstract}

\section{Introduction}

The Arctic sea ice cover is fractured by leads and polynyas in zones of divergence and shear motion. Although the area of these openings is relatively small during winter, they are of major importance for the heat balance. The heat fluxes between open water and the atmosphere are orders of magnitudes larger than the fluxes through thicker ice (Maykut, 1987). Not only leads with open water, but also refrozen leads covered with thin ice contribute to these strong heat fluxes. According to a study by (Lüpkes et al., 2008), a change of the lead fraction by $1 \%$ could cause a near-surface air temperature signal of up to $3.5 \mathrm{~K}$ under clear-sky conditions during polar night.

A very significant positive trend in Arctic sea ice velocity has recently been reported (Hakkinen et al., 2008). A more dynamic sea ice cover exhibits more leads and openings, implying changes in the heat balance and the winter surface air temperature. However, the distribution, variability, and possible trends of openings in the Arctic sea ice cover are not well known.

Traditional passive microwave ice concentration data over the high ice concentration Arctic sea ice have errors and biases that are about one magnitude larger than the true variability (Andersen et al., 2007). Thus, the existing sea ice concentration products are not suitable to study the question if the recent warming in the Arctic is an early response of the system to greenhouse gas loading (Serreze and Francis, 2006). Measurements of sea ice thickness and thin ice distribution are ultimately needed to investigate sea ice related processes responsible for the Arctic amplification.

Mechanisms at the air-ocean interface in the Arctic, such as heat fluxes over sea ice, have a pronounced influence on the entire climate system (Serreze et al., 2009). It is therefore crucial to take leads and their effects into account for boundary layer processes for modelling weather and climate. Leads are also hypothesized as sources of atmospheric sea salt from frost flowers growing on leads (Kaleschke et al., 2004).

Leads develop as elongated cracks of open water in the ice cover. These regions refreeze as they are subjected to severe cooling by the atmosphere. At first, loose ice crystals gather at the water surface (new ice or grease ice). Formation of nilas occurs if no waves are present on the freezing water surface. Nilas ice is a elastic thin ice of crystals that are frozen together. Nilas ice has a thickness up to $10 \mathrm{~cm}$. If 
waves disrupt the formation of an even ice cover, pancake ice forms. New ice, nilas, and pancake ice are denominated as thin ice according to the definition of the World Meteorological Organization (WMO, 1989).

Wensnahan et al. (1993) performed a principal component analysis of thin ice microwave emission spectra and concluded that thin ice can be distinguished from mixtures of open water, first-year ice, and multi-year ice by its spectral characteristics.

Cavalieri (1994) presents a microwave technique to map thin ice. This technique uses polarization ratios of the $19.4 \mathrm{GHz}$ channel and the differences between vertically polarized radiance components at $19.4 \mathrm{GHz}$ and $37.0 \mathrm{GHz}$ channels. Large areas of new ice, young ice, and first year ice are distinguished this way, but the algorithm is limited to seasonal sea ice zones because thin ice and multi-year ice cannot be distinguished by the used channels. Unlike previous studies, this work focuses on the detection of leads covered by thin ice by using the $89 \mathrm{GHz}$ channel of AMSR-E.

A method to detect light nilas, using the AMSR-E $89.0 \mathrm{GHz}$ vertically polarized brightness temperature, was presented in Jacobi et al. (2006). They discovered that light nilas has the highest emissivity at $89.0 \mathrm{GHz}$ when compared to other surface types. Jacobi et al. (2006) used a threshold of $230 \mathrm{~K}$ to detect lead areas covered with light nilas.

A five year lead climatology for the Arctic Ocean was constructed by Miles and Barry (1998) using optical satellite images, where leads were mapped manually. Lindsay and Rothrock (1995) performed an automatic detection of leads using optical satellite imagery. The two methods are able to recognize small leads, but they are not functional during the dark season because visible channels are necessary to identify clouds. Kwok (2002) used ice motion data derived from synthetic aperture radar (SAR) with the well-established RADARSAT Geophysical Processor System (RGPS) to retrieve openings in the ice cover. By comparing the results with passive microwave ice concentration data, Kwok (2002) showed that the ice concentrations do not account for openings in the high concentration ice cover. The openings of $\sim 0.3 \pm 0.1, \%$ in the RGPS product were shown to be one order of magnitude lower than the biases and uncertainties of the passive microwave retrievals.

In the following, we present a simple method to detect thin ice with passive microwave imagery. The algorithm focuses on the detection of leads. We exclude large areas of thin ice, which constitute polynyas and seasonal thin ice covers. They can be detected by other techniques (Cavalieri, 1994; Markus and Burns, 1995; Kern et al., 2005; Tamura and Ohshima, 2011). The data and processing methods used are described in Sect. 2. A way to distinguish thin ice from thicker ice in passive microwave imagery is introduced, as well as a method to extract leads from the images. In Sect. 3, the results are examined and validated qualitatively using MODIS, Envisat ASAR, and CryoSat-2 data.
Table 1. Specifications of used channels from the AMSR-E sensor.

\begin{tabular}{lcc}
\hline Channel & Sensor footprint & NSIDC grid \\
\hline $89.0 \mathrm{GHz}$ & $6 \mathrm{~km} \times 4 \mathrm{~km}$ & $6.25 \mathrm{~km}$ \\
$18.7 \mathrm{GHz}$ & $27 \mathrm{~km} \times 16 \mathrm{~km}$ & $12.5 \mathrm{~km}$ \\
\hline
\end{tabular}

\section{Methods}

\subsection{Passive microwave data}

Passive microwave data from JAXA's AMSR-E sensor on the NASA's Earth Observation System Aqua satellite are used to detect leads in sea ice. The AMSR-E sensor measures microwave radiation (brightness temperatures $T_{\mathrm{B}}$ ) from the earth at six different frequencies while horizontally and vertically polarized radiation is measured separately for each frequency ranging from $6.9 \mathrm{GHz}$ to $89.0 \mathrm{GHz}$.

The National Snow and Ice Data Center (NSIDC) provides daily averages of brightness temperatures $\left(T_{\mathrm{B}}\right)$ from the AMSR-E sensor on polar stereographic grids since the launch of the satellite in 2002 . Vertically polarized brightness temperatures at $18.7 \mathrm{GHz}$ and $89.0 \mathrm{GHz}$ are used in this study, specifications of these are given in Table 1.

In order to have both brightness temperatures on the same grid, $T_{\mathrm{B}} 18.7 \mathrm{GHz}$ is interpolated onto the $6.25 \mathrm{~km}$ grid. This study focuses on the detection of leads in the high ice concentration sea ice cover. The ARTIST Sea Ice (ASI) algorithm uses near $90 \mathrm{GHz}$ channels to retrieve ice concentrations (Kaleschke et al., 2001; Spreen et al., 2008). In this study, ASI ice concentrations are used to distinguish high ice concentration areas from open water.

\subsection{Thin ice in passive microwave imagery}

Eppler et al. (1992) compiled microwave emissivities from different measurements for different sea ice classes in the frequencies typically obtained from space-born satellites. An assortment of those emissivities is visualized in Fig. 1 with the dashed line characterizing an emissivity ratio $r_{\epsilon}=1$ with

$r_{\epsilon}=\frac{\epsilon_{89 V}}{\epsilon_{19 V}}$.

Here, $\epsilon_{89 V}$ and $\epsilon_{19 V}$ denote the emissivities of sea ice at the vertically polarized frequencies $89.0 \mathrm{GHz}$ and $18.7 \mathrm{GHz}$, respectively. It shows that only water and thin ice (i.e. new ice, nilas, and pancake ice) exhibit emissivity ratios above one, thus giving the possibility to distinguish thin ice from other ice types. However, light nilas, the thickest thin ice class, remains difficult to distinguish from thicker ice classes when using $r_{\epsilon}$. Summer surface melting in general is problematic for passive microwave sea ice retrievals. Melted surfaces appear with an emissivity ratio close to one. 


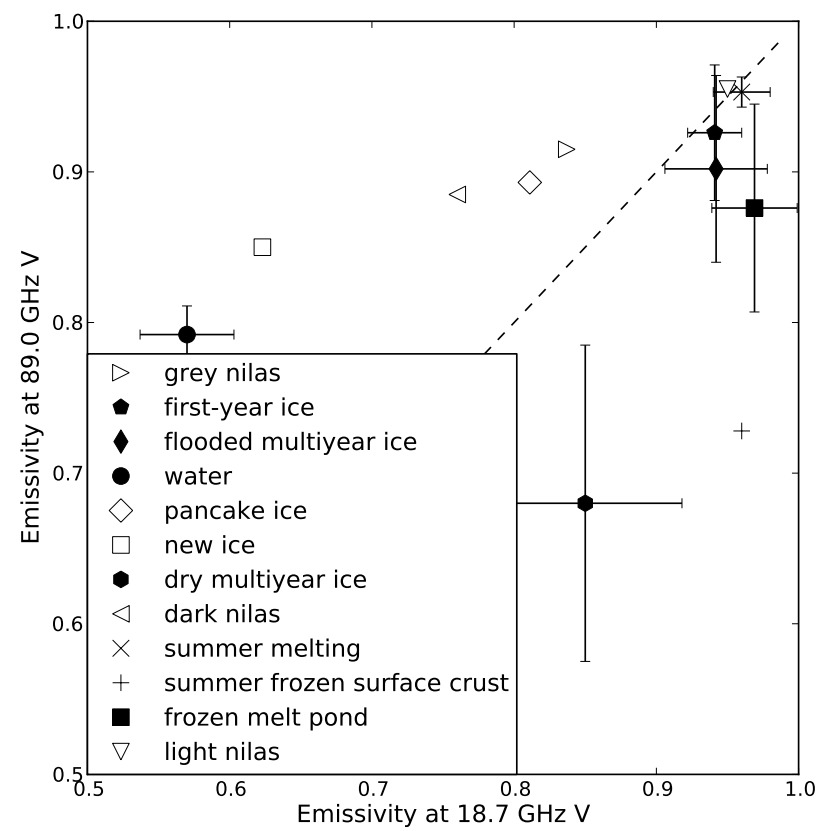

Fig. 1. Emissivities of different sea ice classes in a comparison of the vertical polarized frequencies $18.7 \mathrm{GHz}$ and $89.0 \mathrm{GHz}$. Thin ice classes are plotted with contoured markers, other ice classes and open water with solid markers. The dashed line shows an emissivity ratio of $r_{\epsilon}=1$. The values are taken from Eppler et al. (1992). The error bars display standard deviations if available.

The retrieval of surface emissivities at the frequency $v$ from the measured brightness temperatures $T_{\mathrm{B}, v}$ requires radiative transfer modelling in the atmosphere and snow, as well as priori information about the atmospheric state (Mathew et al., 2008; Harlow , 2011). In the following, we completely neglect the atmospheric contribution since later we apply a spatial high-pass filter that effectively reduces the atmospheric influence. Thus, we simply express the brightness temperature $T_{\mathrm{B}, \nu}$ by the effective emitting surface temperature $T_{\mathrm{B}}$ and the emissivity $\epsilon_{\nu}$ :

$T_{\mathrm{B}, \nu}=\epsilon_{v} T_{\mathrm{S}}$.

In order to reduce the effect of a varying surface temperature, the emissivity ratio $r_{\epsilon}$ is represented by a brightness temperature ratio $r$ :

$r_{\epsilon}=\frac{\epsilon_{89 V}}{\epsilon_{19 V}} \simeq \frac{T_{\mathrm{B}, 89 V}}{T_{\mathrm{S}}} \cdot \frac{T_{\mathrm{s}}}{T_{\mathrm{B}, 19 V}}=\frac{T_{\mathrm{B}, 89 V}}{T_{\mathrm{B}, 19 V}}=r$

The use of this ratio reduces the effect of a varying surface temperature, however it neither accounts for the variation of the vertical temperature gradient within the emitting snow and ice layer nor for the implicit dependency of the emissivity on the temperature.

As shown in Fig. 1, $r_{\epsilon}$ enables a distinction between thin ice anc of $r$, as defined in Eq. (3), is displayed in Fig. 2 for the central Arctic. As expected from Fig. 1, regions of open water, coastal polynyas, and large leads are characterized by $r>1$. However, atmospheric attenuation and the effect of the variations of the vertical temperature gradient within snow and ice also have the potential to significantly change the ratio $r$ and, therefore, cannot be neglected.

\subsection{Spatial filtering}

The use of the following filter is twofold. Firstly, it separates the surface from the atmospheric signal due to their different spatial scales. Secondly, it enhances the signal of the leads.

A closer examination of Fig. 2 shows that presumptive leads, which are linear features in the ice cover, do not always have $r$ values above one. The profile (Fig. 2b) at the red line in Fig. 2a crosses four leads and confirms that $r$ at the leads is just above 0.88 even though the physically expected value is $r>1$. The large footprint of the AMSR-E sensors (compare Table 1) causes a signal of a narrow lead to appear as a mixture between a lead signal and a thick ice signal. Leads that are narrower than the sensor's footprint, cannot therefore be solely characterized by their $r$ value but rather by their appearance as $r$ anomalies $\left(r^{\prime}\right)$. More precisely, leads are regions with high $r$ values surrounded by lower $r$ values of thick ice. This may be expressed by the relation $r=\bar{r}+r^{\prime}$. A high-pass filter is implemented to retrieve $r^{\prime}$ :

$r^{\prime}=r-\operatorname{Median}_{w}(r)$

A median filter is used to represent $\bar{r}$, because it has proven to detect leads better than linear shift invariant (LSI) filters (Arias-Castro and D.L. Donoho, 2009). It removes anomalies such as leads but preserves edges between large constant areas. A LSI edge detection filter did not exclusively deliver lead regions but also edges between other thick ice classes, ice edges to open water, and edges to large atmospheric disturbances.

The median operator in Eq. (4) replaces the center pixel of a search window with the median value of all pixels within the search window. The size of the search window is a $w \times w$ pixel. The parameter $w$ needs to be optimized for sensor characteristics.

\subsection{Definition of thin ice concentration}

Leads are recognized by their thin ice cover. Analogue to sea ice concentration, a thin ice concentration (TIC) is defined to describe the area fraction of thin ice compared to other ice classes. The TIC is defined as follows: An upper tie-point $r_{100}^{\prime}$ of the $r^{\prime}$ value sets a TIC of $100 \%$, and a lower tie-point $r_{0}^{\prime}$ sets a TIC of $0 \%$. In between the two tie-points, the TIC is linearly interpolated.

$\mathrm{TIC}= \begin{cases}1 & \text { if } r^{\prime}>r_{100}^{\prime} \\ 0 & \text { if } r^{\prime}<r_{0}^{\prime} \\ \frac{r^{\prime}-r_{0}^{\prime}}{r_{100}^{\prime}-r_{0}^{\prime}} & \text { if else }\end{cases}$ 

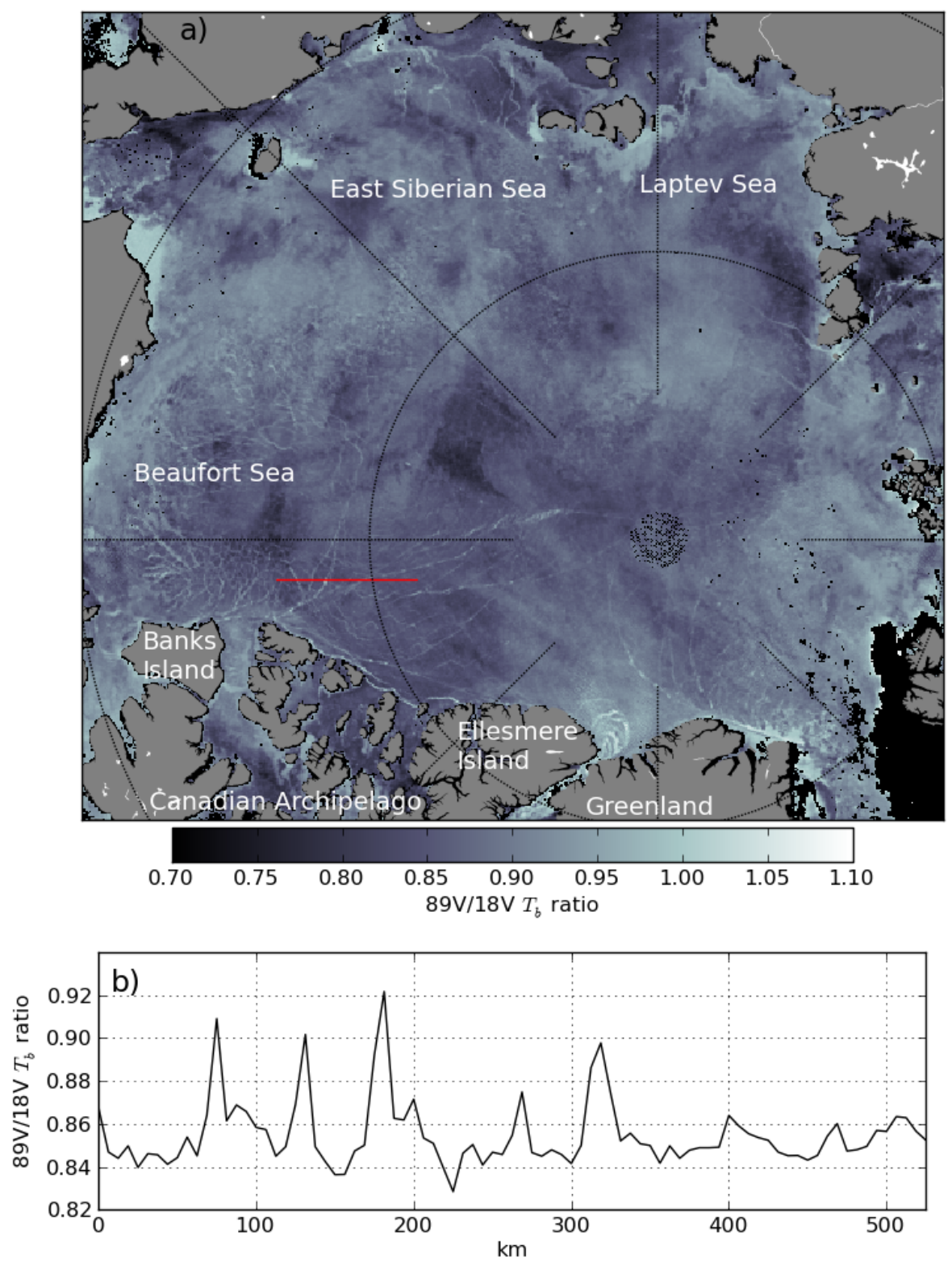

Fig. 2. (a) Brightness temperature ratio $r$ of the $89.0 \mathrm{GHz} \mathrm{V}$ and $18.7 \mathrm{GHz} \mathrm{V}$ channels at the 27.02.2007. in the Arctic Ocean. (b) $r$ profile at the red line.

In order to focus on leads in the closed ice cover, pixels containing more than $10 \%$ of open water according to ASI ice concentration are not considered. The threshold of $10 \%$ is chosen to blend out the ice edge. However, pixels with $r$ values that correspond to open water are not sorted out by the algorithm. Therefore, open water regions that are not classified as open water according to ASI ice concentrations are assigned with high TIC.

\section{Results}

\subsection{Adjustment of algorithm parameters using MODIS data}

All parameters, these being window size $w$ of the median filter as well as the upper, and the lower tie-points in the TIC definition, are obtained by comparing the respective results of TICs with visible satellite images. In visible satellite images, open water and thin ice appear as dark regions due to low reflectance. For cloud free daylight conditions, the high resolution of visible satellite images enables a reliable identification of leads. 


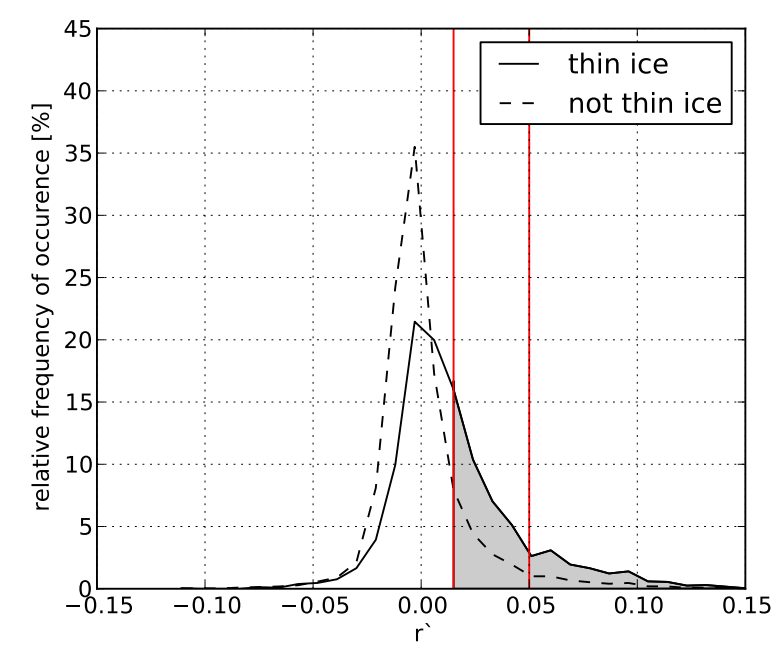

Fig. 3. Frequency distribution of $r^{\prime}$ values for the scene in Fig. 5a. The red lines mark the lower and upper tie-points $r_{0}^{\prime}$ and $r_{100}^{\prime}$ in Eq. (5).

The Moderate Resolution Imaging Spectroradiometer (MODIS) aboard the Aqua EOS and Terra EOS satellites acquires data in 36 different spectral bands. Band 3 of the MODIS sensor $(459 \mathrm{~nm}-479 \mathrm{~nm})$ has a spatial resolution of $500 \mathrm{~m}$ and is used on the one hand to determine the parameters mentioned above and on the other hand for validation of the TIC product. In order to evaluate whether the computed TICs do indeed mark thin ice regions, TICs are overlaid onto MODIS band 3 images.

The search window size $w$ in Eq. (4) is optimized to detect leads. Too small search windows cannot detect broad leads, while too large search windows disturb small scale lead signals if several leads are close together. A comparison of results with different $w$ showed satisfying results for values of 5,7 and 9 pixel. Therefore $w=7$ is used, corresponding to an area of $44 \mathrm{~km} \times 44 \mathrm{~km}$.

Figure 3 shows a frequency distribution of $r^{\prime}$ values for thin ice pixels as well as for pixels that do not contain thin ice. Here, visible satellite imagery is used to determine if pixels contain thin ice or not. Thin ice is classified by a reflectance lower than 0.65 in band 3 of the MODIS sensor. In Fig. 3, values for $r^{\prime} \gtrsim 0.05$ are only present for thin ice, indicating that the area represented by those pixels only contains thin ice. $r^{\prime}=0.05$ is therefore used as a tie-point for $100 \%$ thin ice concentration.

The validation in Sect. 3.3 shows that the upper tiepoint generally offers reasonable results. The validation also demonstrates that $r^{\prime}=0.015$ as a lower tie-point enables the detection of even smaller leads while keeping noise on a low level.

\subsection{Lead distribution patterns}

Daily thin ice concentrations (TICs) for the northern hemisphere are calculated from September 2002 until October 2011 excluding the summer months June, July and August, where the algorithm cannot be applied. Examples for TIC maps are shown in Fig. 4.

The following features dominate the TIC maps: (A) linear features of high TIC (leads) are present in most of the TIC maps. Leads often appear between the North Pole and the Fram Strait, as in Fig. 4a, b, d, and north of the Canadian Archipelago and Greenland (Fig. 4a, b, c). (B) Irregular structures of TIC are very often present in the Beaufort Sea. (C) Coastal polynyas are often visible at the Canadian Archipelago, in the Laptev Sea and in the East Siberian Sea.

Looking at series of subsequent TIC maps, the following impression appears: (D) Leads remain present several days after their appearance, are strongly subjected to the ice movement and deformation, then disappear suddenly (from one day to another). (E) The irregular structures of TIC in the Beaufort Sea are usually caused by the rotation of the Beaufort Gyre described by (Rigor et al., 2002). (F) Coastal polynyas are stationary features and remain present for more than a few days.

Some specific lead patterns, which recurred frequently from September 2002 until October 2011, are found in the TIC maps: G) Parallel circle segments of leads are located stream upwards of outflow passages of sea ice from the Arctic Ocean. This pattern frequently occurs north of the Fram Strait, as visible in Fig. 4a, d. On a smaller scale, this pattern frequently occurs north of the Nares Strait which is located between the northern edge of Greenland and Ellesmere Island (Fig. 4c). H) The frequently occurring coastal polynyas at the Canadian Archipelago tend to be extended through larger leads, pointing away from land. These leads are oriented towards north or north-east (Fig. 4b).

\subsection{Validation of thin ice concentrations using MODIS data}

In this investigation, the detection of leads is considered as the primary usage of the TIC maps. Therefore, the validation of TIC focuses on linear structures of thin ice (presumptive leads).

Figure 5 shows scenes from the Beaufort Sea during different seasons. Banks Island is located in the lower left hand corner of all three images, some parts of the Queen Elisabeth Island are located in the lower right hand corner.

Figure 5a displays a scene of the 21st of March, 2006. Broad leads overlap with high TIC and some of the narrow leads are covered by low TIC. However, most of the narrow leads are not detected. A few pixels of low TIC are present at places where no thin ice or water is visible in the optical image, for instance in the upper right quadrant of Fig. 5a. These pixels must be regarded as failures of the lead detection. A 

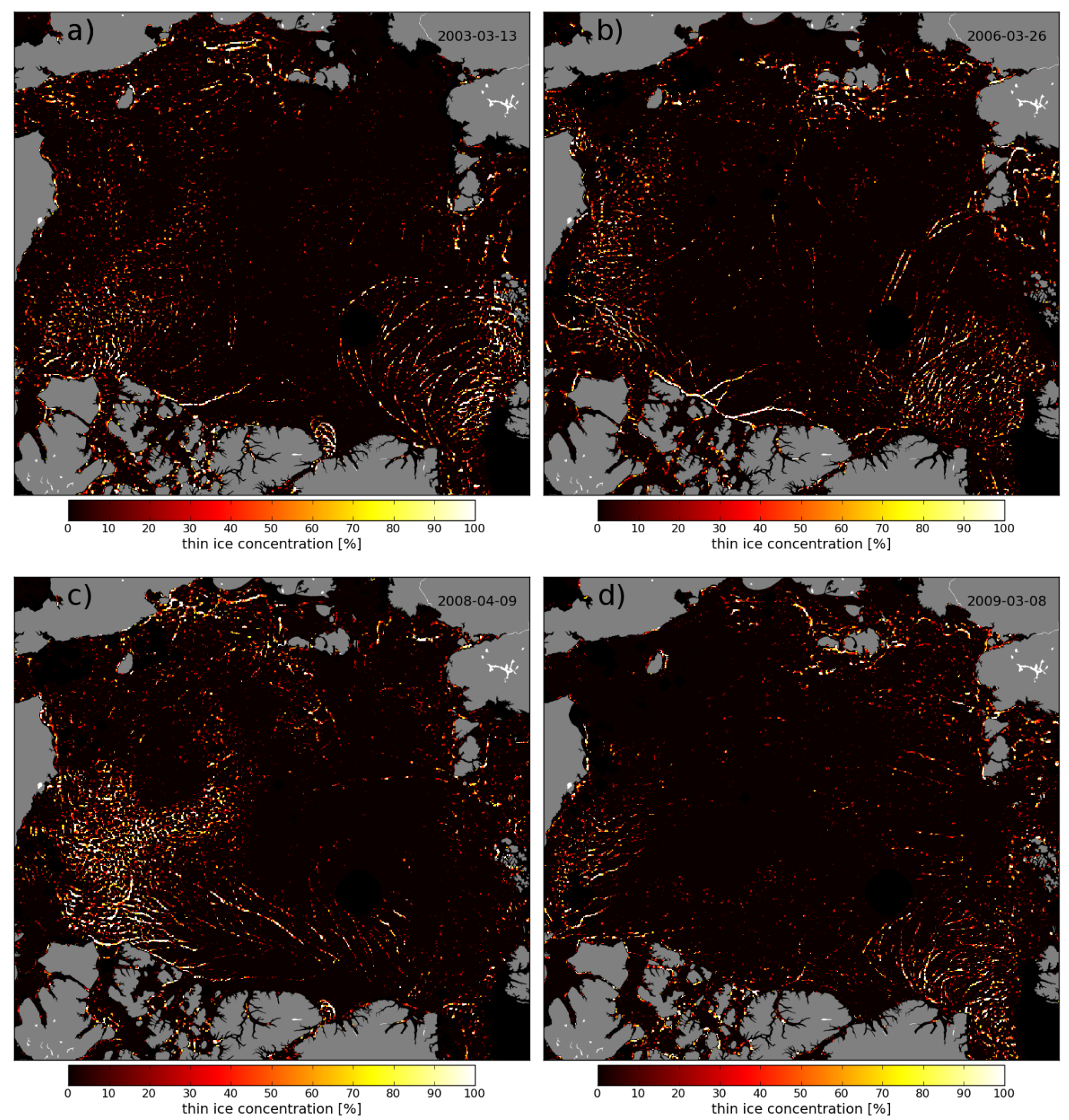

Fig. 4. Thin ice concentrations in the Arctic Ocean as defined in Sect. 2.4.

polynya at Banks Island can be seen in Fig. 5a, where the TIC is low in some parts of the polynya. This will be discussed in Sect. 4.

Figure $5 b$, c illustrates similar relations between optical images and TICs as in Fig. 5a. An autumn scene (25th of September, 2007) from the same region as in Fig. 5a is shown in Fig. 5b. Here, the ice edge is located in the image. Many leads are visible in the optical image, most of them appear in a pattern of parallel circle segments. This pattern can be identified in the TIC as well.

A scene of May 3rd, 2007 is displayed in Fig. 5c. Here, Ellesmere Island is located in the lower right corner. Large leads are recognized by the thin ice detection while the polynya near Banks Island is not marked as thin ice (compare Fig. 5a).
These results were obtained with the parameters given in Sect. 3.1. The linear structures of high TIC, found in Fig. 4 and described in Sect. 3.2, can indeed be identified as leads. The smallest lead detected with certainty is $3 \mathrm{~km}$ wide. This number is determined by measuring the width of the leads in Fig. 5a manually. In this scene, all leads broader than $3 \mathrm{~km}$ were marked by a TIC larger than $5 \%$. Occasionally, smaller leads were detected.

Each TIC pixel in Fig. 5a, c was evaluated, whether it contains thin ice or not, according to the corresponding MODIS image as described in Sect. 3.1. This information was used to obtain a distribution of $r^{\prime}$ values for all pixels, thin ice as well as non-thin ice (Fig. 3). Consequently, the new lead detection algorithm classifies all pixels with $r^{\prime}$ values above the lower tie-point $r_{0}^{\prime}$ (left red line) as thin ice. The shaded 

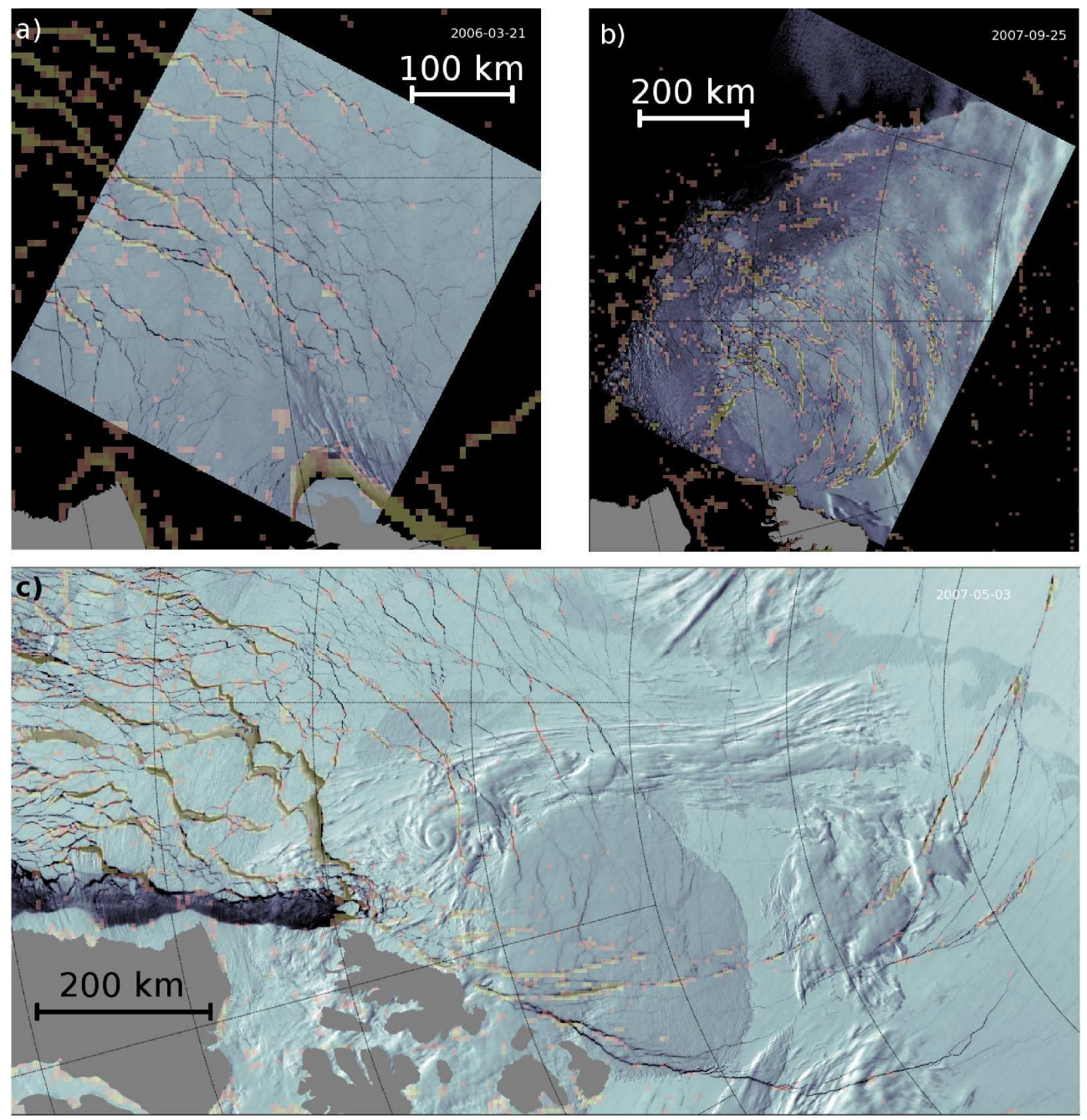

Fig. 5. Comparison of thin ice concentrations with optical satellite images (MODIS band 3). The optical images are displayed in gray-scale, TICs are displayed in opaque color from reddish $(5 \%)$ to yellow $(100 \%)$. The TIC pixel cover an area of $6.25 \mathrm{~km} \times 6.25 \mathrm{~km}$.

area underneath the thin ice curve in Fig. 3 represents thin ice containing pixels that were identified by the lead detection. The area underneath the entire thin ice curve represents pixels containing leads according to the MODIS image. The ratio between these areas gives an estimate of how many thin ice containing pixels were found by the lead detection compared to how many pixels are identifiable as thin ice pixels in the MODIS image. In the investigated scene, about $50 \%$ of the thin ice containing pixels were detected by the lead detection algorithm.

\subsection{Validation of thin ice concentrations using ASAR and CryoSat-2 data}

Hundreds of Envisat ASAR wide swath mode (WSM) images obtained from ESA's rolling archive have been used to assess the quality of the AMSR-E thin ice concentration method. For the period of February to May 2011, the WSM
ASAR data have been calibrated, geocoded, and visualized together with the AMSR-E thin ice concentration. In addition, we used Level 1B CryoSat-2 data to derive the positions of specular reflecting surfaces which indicate the presence of leads. The maximum return power of the CryoSat-2 radar signal is used for surface classification. When the power exceeds a threshold value of $6 \times 10^{-10} \mathrm{~W}$, we assume that the surface within the CryoSat-2 footprint is a lead surface. Figure 6 shows an example of how the data are combined and visualized. Because the radar backscatter signature of leads is highly variable depending on wind speed and the presence of frost flowers, an automatic lead classification is very difficult. Thus, our analysis is based on visual inspection of the images and remains qualitative. From the analysis of the combined AMSR-E, ASAR, and CryoSat-2 images we learn that when a lead is detected by the lead detection algorithm in the AMSR-E data, the corresponding structure is very likely to be found in the ASAR image as well as in the CryoSat-2 


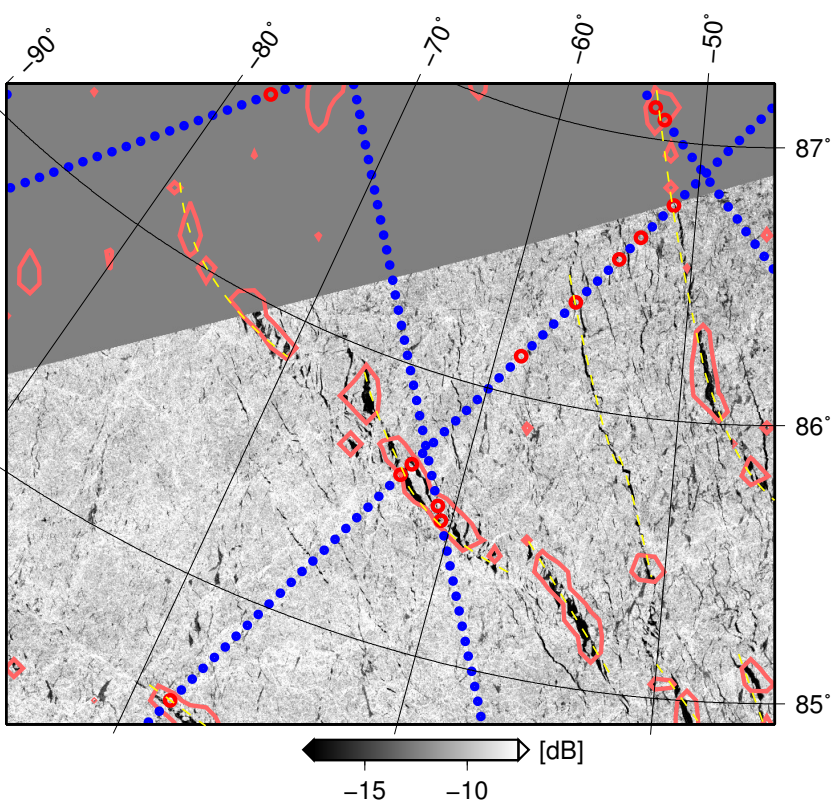

Fig. 6. AMSR-E thin ice concentration isolines (50\%, light red), ASAR WSM image (gray), and CryoSat-2 surface classification (red and blue dots) on 23 February 2011. The CryoSat-2 surface classification represents an average of 20 stacked measurements to match the $6.25 \mathrm{~km}$ spatial resolution of the AMSR-E grid. The hand-drawn splines (thin yellow dashed lines) visualize connected lead structures that are simultaneously detected in the AMSR-E, ASAR and CryoSat-2 data.

track. Vice versa, this is not always the case due to the fact that the ASAR and CryoSat-2 resolution is much finer. The ASAR WSM pixels have a resolution of $150 \mathrm{~m}$ and the CryoSat-2 footprint is about $250 \mathrm{~m}$. Overall, the comparison with ASAR and CryoSat-2 does not offer additional insights when compared to the previous validation with MODIS data.

\section{Discussion}

This study presents a way to distinguish thin ice from other ice types by using microwave imagery. Two different frequencies from the AMSR-E sensor are combined to one ratio in which thin ice theoretically has significant values above one. The ratio involves two channels with different sensor footprints. The resolution of the $18.7 \mathrm{GHz}$ channel is generally too coarse to resolve lead structures. Thus, the ratio usually represents a mixture of surface types. The algorithm detects leads smaller than the $6 \mathrm{~km} \times 4 \mathrm{~km}$ resolution of the 89.0 GHz footprint. This ability is caused by the strong emissivity contrast between thin ice and thicker ice and additionally is enhanced by the use of a high-pass filter. We note that lead structures can also be detected using the $89.0 \mathrm{GHz}$ brightness temperature and the high-pass filter alone. However, using the ratio has the advantage of the respective tiepoints being more stable.
Because of this high-pass filter, the lead detection algorithm presented here does not detect large areas of thin ice. For example, coastal polynyas can be seen in Fig. 5a and c. At the broadest part of the polynya in Fig. 5a, the TIC decreases to low values. The large polynya in Fig. $5 \mathrm{c}$ is marked with zero TIC. At narrow parts of the polynyas, the TIC has reasonable high values. The TIC algorithm does not detect large regions of thin ice due to the fact that the algorithm uses a spatial high-pass filter. It enables the detection of sub-pixel scale leads but causes the algorithm to overlook larger thin ice areas. The lead detection presented here is optimized to detect narrow leads. Other techniques exist to recognize large areas of thin ice and polynyas (Cavalieri, 1994; Markus and Burns, 1995; Kern et al., 2005; Tamura and Ohshima, 2011). The ratio of the $89.0 \mathrm{GHz}$ and $18.7 \mathrm{GHz}$ channels used here could in principle be applied to detect large areas of thin ice if the spatial filter would not be implemented. However, the significant influence of the atmospheric variability restrains this approach.

Wensnahan et al. (1993) concluded that small areas of thin ice cannot be detected by passive microwave imagery due to their low resolution. The technique presented in this study uses the $89 \mathrm{GHz}$ channel of the AMSR-E sensor with a considerable higher resolution than other microwave channels. Together with the spatial filter, this channel even enables the distinction of sub-pixel scale occurrences of thin ice from other ice classes. In particular, leads covered by thin ice can be detected by the presented technique. Optical satellite images showed that leads with a width of $3 \mathrm{~km}$ or wider are detected fairly well. $50 \%$ of the lead area in MODIS images are identified as lead pixels by the passive microwave algorithm.

Figure 4 shows high thin ice concentrations at coasts that represent polynyas but could also originate from land microwave emissions. A technique to reduce the effect of coasts on microwave imagery is developed by Maaß and Kaleschke (2010). However, the validation of TICs with MODIS and ASAR images in fact displayed coastal polynyas in the examined scenes.

The presented lead detection can be applied when AMSRE passive microwave imagery with the high resolution $89 \mathrm{GHz}$ channel is available. This includes the entire Arctic and Antarctic on a daily basis due to the fact that no daylight is required and clouds cause no serious limitation. The lead detection cannot be applied during the summer months (June, July, August) because surface melting modifies the ice emissivity. This becomes obvious when looking at the emissivities of the summer melting ice class in Fig. 1, here summer melting has a similar emissivity ratio as nilas. Furthermore, high atmospheric moisture during summer affects the signal of the $89 \mathrm{GHz}$ channel.

Earlier lead detection studies used optical or SAR data to locate leads (Miles and Barry, 1998; Kwok, 2002). The high resolution of optical and SAR data reveals leads that are orders of magnitudes smaller than the leads detected in this 
study. However, the new lead detection using passive microwave data enables an investigation of leads with a better temporal coverage. In further studies, the new lead detection could be used to investigate the dynamical processes that cause the formation of leads.

The selected TIC examples (Fig. 4) highlight areas where leads often occur. A region with considerable high lead occurrence is the Beaufort Sea which is in accordance with the results of Miles and Barry (1998). Rigor et al. (2002) described the ice drift in the Beaufort Sea, which follows the rotational movement of the Beaufort Gyre. Rigor et al. (2002) explained that the anticyclonic motion in the atmosphere causes divergent Ekman transport at the sea surface, leading to the formation of leads and thinning of sea ice. This explains the high average TIC in the Beaufort Sea. Accordingly, regions of low ice deformation also show low average TIC, i.e. the inner Arctic Ocean where the less deformational transpolar ice drift is located (Rigor et al., 2002).

Other regions with high TICs were located upstream of outflow passages of sea ice from the Arctic Ocean such as the Fram Strait and the Nares Strait. In these two regions, parallel circle segments of leads are often present. These parallel circle segments, also referred to as arches, result from the outflow of ice through lateral boundaries on both sides. The formation of arch-shaped leads due to displacement restrictions at the region boundaries has been described by Goldstein et al. (2000). Kwok et al. (2010) investigated the ice outflow through the Nares Strait using SAR images and concluded that the arches of ice slow down the ice export through the passage because of their structural strength.

In this study, regions with ASI ice concentrations below $90 \%$ are excluded. Therefore, all detected leads coincide with higher total ice concentrations. The thin ice concentration defined here could therefore serve as a useful additional tool beside the total ice concentration to describe the surface properties of sea ice covered oceans. In particular, if surface energy fluxes are to be estimated, the total ice concentration does not represent the diverse conditions of thin ice and thicker ice.

\section{Conclusions}

Based on microwave emission properties of sea ice, a method to detect sea ice leads is presented. Thin ice has a unique signature in the ratio of the brightness temperatures at $89 \mathrm{GHz}$ and $19 \mathrm{GHz}$. The algorithm allows the detection of thin ice covered leads, open water leads and polynyas that are broader than $3 \mathrm{~km}$. $50 \%$ of the total lead area visible in $500 \mathrm{~m}$ resolution optical satellite images is detected by the algorithm. The leads that are detected coincide with the total high ice concentrations. Therefore, the new thin ice product delivers additional information for the description of surface properties of the Arctic Ocean, especially if heat fluxes are to be estimated.
During 2002 to 2011, leads and other thin ice features were located mainly in the Beaufort Sea and close to the Fram Strait, where average TICs were up to $20 \%$. The inner Arctic Ocean close to the north pole showed low lead occurrence with average TICs below $2 \%$. Smaller areas of high average TICs were found stream upwards of the Nares Strait and close to coasts, where coastal polynyas are often present.

Frequently reoccuring patterns of leads were identified, i.e. parallel circle segments of leads stream-upwards of the Fram Strait and the Nares Strait or leads that are extensions of coastal polynyas. The detected leads had a duration time of several days and were strongly subject to ice drift and deformation, especially in the rotational movement in the Beaufort Sea.

Acknowledgements. This work has been funded by the German Science Foundation (DFG) via SFB512, Teilprojekt E5. We thank the reviewers and the editor for their critical suggestions, as well as Lisa Schneider for copy-editing the manuscript.

Edited by: E. Hanna

\section{References}

Arias-Castro, E. and Donoho, D. K.:Does median filtering truly preserve edges better than linear filtering?, Annals of Statistics, 37, 1172-1206, doi:10.1214/08-AOS604, 2009.

Andersen, S., Tonboe, R., Kaleschke, L., Heygster, G., and Pedersen, L.: Intercomparison of passive microwave sea ice concentration retrievals over the high-concentration Arctic sea ice, J. Geophys. Res, 112, C08004, doi:10.1029/2006JC003543, 2007.

Cavalieri, D.: A microwave technique for mapping thin sea ice, J. Geophys. Res.-Oceans, 99, 12561-12572, 1994.

Eppler, D., Farmer, L., Lohanick, A., Anderson, M., Cavalieri, D., Comiso, J., Gloersen, P., Garrity, C., Grenfell, T., Hallikainen, M., Maslanik, J., Mätzler, C., Melloh, R., Rubinstein, I., and Swift, C.: Passive microwave signatures of sea ice, in: Microwave Remote Sensing of Sea Ice, edited by: Carsey, F. D., no. 68 in Geophysical Monograph, American Geophysical Union, 1992.

Goldstein, R. V., Osipenko, N. M., and Leppäranta, M.: Classification of Large-Scale Sea Ice Structures Based on Remote Sensing Imagery, Geophysica, 36, 95-109, 2000.

Hakkinen, S., Proshutinsky, A., and Ashik, I.: Sea ice drift in the Arctic since the 1950s, Geophys. Res. Lett., 35, L19704, doi:10.1029/2008GL034791, 2008.

Harlow, R. C.: Sea Ice Emissivities and Effective Temperatures at MHS Frequencies: An Analysis of Airborne Microwave Data Measured During Two Arctic Campaigns, IEEE T. Geosci. Remote, 49, 1223-1237, 2011.

Jacobi, H., Kaleschke, L., Richter, A., Rozanov, A., and Burrows, J.: Observation of a fast ozone loss in the marginal ice zone of the Arctic Ocean, J. Geophys. Res.-Atmos., 111, D15309, doi:10.1029/2005JD006715, 2006.

Kaleschke, L., Heygster, G., Lüpkes, C., Bochert, A., Hartmann, J., Haarpaintner, J., and Vihma, T.: SSM/I sea ice remote sens- 
ing for mesoscale ocean-atmosphere interaction analysis: Ice and icebergs, Can. J. Remote Sens., 27, 526-537, 2001.

Kaleschke, L., Richter, A., Burrows, J., Afe, O., Heygster, G., Notholt, J., Rankin, A. M., Roscoe, H. K., Hollwedel, J., Wagner, T., Jacobi, H. W., Frost flowers on sea ice as a source of sea salt and their influence on tropospheric halogen chemistry, Geophys. Res. Lett., 31, L16114, doi:10.1029/2004GL020655, 2004.

Kern, S., Harms, I., Bakan, S., and Chen, Y.: A comprehensive view of Kara Sea polynya dynamics, sea-ice compactness and export from model and remote sensing data, Geophys. Res. Lett., 32, L15501, doi:10.1029/2005GL023532, 2005.

Kwok, R.: Sea ice concentration estimates from satellite passive microwave radiometry and openings from SAR ice motion, Geophys. Res. Lett., 29, 1311, doi:10.1029/2002GL014787, 2002.

Kwok, R., Pedersen, L. T., Gudmandsen, P., and Pang. S. S.: Large sea ice outflow into the Nares Strait in 2007, Geophys. Res. Lett., 37, L03502, doi:10.1029/2009GL041872, 2010.

Lindsay, R. and Rothrock, D.: Arctic sea ice leads from advanced very high resolution radiometer images, J. Geophys. Res.-Oceans, 100, 4533-4544, 1995.

Lüpkes, C., Vihma, T., Birnbaum, G., and Wacker, U.: Influence of leads in sea ice on the temperature of the atmospheric boundary layer during polar night, Geophys. Res. Lett., 35, L03805, doi:10.1029/2007GL032461, 2008.

Maaß, N. and Kaleschke, L.: Improving passive microwave sea ice concentration algorithms for coastal areas - Applications to the Baltic sea, Tellus A, 62, 393-410, 2010.
Markus, T. and Burns, B.: A method to estimate subpixel-scale coastal polynyas with satellite passive microwave data, J. Geophys. Res.-Oceans, 100, 4473-4487, 1995.

Mathew, N., Heygster, G., Melsheimer, C. and Kaleschke, L.: Surface Emissivity of Arctic Sea Ice at AMSU Window Frequencies, IEEE T. Geosci. Remote, 46, 2298-2306, 2008.

Maykut, G.: Energy exchange over young sea ice in the central Arctic, J. Geophys. Res.-Oceans, 83, 3646-3658, 1987.

Miles, M. and Barry, R.: A 5-year satellite climatology of winter sea ice leads in the western Arctic, J. Geophys. Res.-Oceans, 103, 21723-21734, 1998.

Rigor, I. G., Wallace, J. M., and Colony, R. L.: Response of Sea Ice to the Arctic Oscillation, J. Climate, 15, 2648-2662, 2002.

Serreze, M. and Francis, J.: The Arctic amplification debate, Climatic Change, 76, 241-264, 2006.

Serreze, M. C., Barrett, A. P., Stroeve, J. C., Kindig, D. N., and Holland, M. M.: The emergence of surface-based Arctic amplification, The Cryosphere, 3, 11-19, doi:10.5194/tc-3-11-2009, 2009.

Spreen, G., Kaleschke, L., and Heygster, G.: Sea ice remote sensing using AMSR-E 89 GHz channels, J. Geophys. Res, 113, C02S03, doi:10.1029/2007GL032461, 2008.

Tamura, T. and Ohshima, K.I.: Mapping of sea ice production in the Arctic coastal polynyas, J. Geophys. Res, 116, C07030, doi:10.1029/2010JC006586, 2011.

Wensnahan, M., Maykut, G., Grenfell, T., and Winebrenner, D.: Passive microwave remote sensing of thin sea ice using principal component analysis, J. Geophys. Res.-Oceans, 98, 1245312468, 1993.

WMO: The World Meteorological Organization Sea Ice Nomenclature (WMO No. 259, TP-145, Supplement No. 5), 1989. 